\title{
Thermal comfort optimisation of vernacular rural buildings: passive solutions to retrofit a typical farmhouse in central Italy
}

\author{
Maria Elena Menconi,, ${ }^{1}$ Massimo Chiappini, ${ }^{1}$ Jan L.M. Hensen, ${ }^{2}$ David Grohmann' \\ ${ }^{1}$ Department of Agricultural, Food and Environmental Sciences, Landscape and Rural Buildings Research Unit, \\ University of Perugia, Italy; ${ }^{2}$ Department of the Built Environment, Eindhoven University of Technology, Eindhoven, \\ The Netherlands
}

\begin{abstract}
An adequate retrofitting of traditional rural buildings requires to preserve their formal characteristics and to understand the constructive elements that compose them and which are different in different geographical areas. This paper analyses the typical farmhouses in central Italy. Starting from the definition of a vernacular building model, the paper analyses its performance in terms of thermal comfort and energy efficiency. The methodology involves the use of energy dynamic simulations coupled with optimisation techniques aimed to identify the best combinations of insulating materials in terms of choice of material and its optimal location in the envelope. The paper demonstrates the good thermal and energy performance of farmhouses in central Italy. The results of the optimisation process showed that in these buildings, with the addition of insulation materials with low conductivity the perceived discomfort in the inhabited areas of the building can be reduced by $79 \%$ and the energy consumption related to heating can be reduced by $77 \%$. The level of insulation of the pavement that separates the ground and first floor needs to be more moderate to promote the heat flow between floors during summer. The sensitivity analysis shows that the most influential component for thermal comfort is the roof insulation.
\end{abstract}

\footnotetext{
Correspondence: Maria Elena Menconi, Department of Agricultural, Food and Environmental Sciences, Landscape and Rural Buildings Research Unit, University of Perugia, Borgo XX giugno 74, 06100 Perugia, Italy.

Tel.: +39.075.5856024 - Fax: +39.075 .5856086$

E-mail: mariaelena.menconi@unipg.it
}

Key words: Rural heritage; adaptive comfort model; Fanger model; genetic algorithm; envelope's insulation; building insulation materials.

Received for publication: 10 January 2017.

Accepted for publication: 3 April 2017.

CCopyright M.E. Menconi et al., 2017

Licensee PAGEPress, Italy

Journal of Agricultural Engineering 2017; XLVIII:668

doi:10.4081/jae.2017.668

This article is distributed under the terms of the Creative Commons Attribution Noncommercial License (by-nc 4.0) which permits any noncommercial use, distribution, and reproduction in any medium, provided the original author(s) and source are credited.

\section{Introduction}

\section{Vernacular buildings in rural landscape of central Italy}

Among the assets in European rural areas, the traditional widespread vernacular building has extreme value as an element of identity that can narrate different space-time modality of land management and social organisation. The landscape of central Italy (Umbria, Tuscany, Marche and Abruzzo regions) has been shaped from the middle Ages until the first half of the last century, by the sharecropping agricultural system characterised by the presence of a large number of small fields grown by one or two families living in houses built within the field. This typical farmhouse is called casa colonica (CC) (Italian words for traditional farmhouse of central Italy), where the colono was the farmer who lived and worked in the house but who did not have the property of the fields and of the building. Typically, the farmer established a contract with the owner where it was decided the amount of agricultural products he had to provide and any additional tax (Bonasera et al., 1955). The study of rural buildings is strictly connected with the surrounding context. In fact the farmer lived in close contact with the agricultural land and animal husbandry and he needed low cost solutions to construct the buildings (Menconi et al., 2017).

The object of the present study is a particular kind of vernacular building, called in this paper CC (casa colonica) because in English language does not exists an adequate translation.

In the last fifty years, in the transition from a traditional rural society to the modern industrial one, the rural landscape undergone deep changes in production techniques and in agricultural and economic policies. These changes have pushed towards intensive cropping and farming systems that have inevitably influenced the occupancy and use of existing rural buildings. Those unable to meet the changing needs of productivity, quality of life and work have gone through a process of alteration, underuse, abandonment and demolition. General trends have gone towards the manufacture of new rather than the recovery of old buildings, for cost reasons, execution time or simply for functional incompatibility (Torreggiani and Tassinari, 2013). The abandonment process has risen various issues, such as: the loss of local identity due to the flattening of building typology; the loss of a historical and cultural background; the loss of technological knowledge related to the traditional specialised craftsmanship; the impairment of the agricultural landscape where modern buildings are mixed with abandoned historical buildings (Torreggiani and Tassinari, 2013).

European Community and national trends favour and encourage the process of recovery and refurbishment of the built environment following tree main lines: valorisation of the cultural 
heritage, reduction of land consumption and increasing buildings energy efficiency.

\section{Vernacular rural buildings as cultural heritage}

The vernacular buildings scattered in rural landscape play a significant role as keys to the interpretation of the past and as elements of cultural heritage. The Convention for the Protection of the Architectural Heritage of Europe (1985) recalls the importance of handing down to future generations a system of cultural references, improving the urban and rural environment (preamble of the Convention). The European Landscape Convention (2000) gives a new dignity to rural landscape, which heritage value derived from its natural configuration and/or from human activity. The European Recommendation $\mathrm{CM} / \operatorname{Rec}(2008) 3$ requires that the approaches to historic monuments need to be the subject of particular plans or of regulations designed to preserve the physical, historical, symbolic, visual and compositional relationship with close and distant contexts. The originality of the vernacular buildings corresponds to what happens to farming practices in different context (Picuno, 2012). Generally, the traditional buildings are representative of the identity of a community and many traditional farming landscapes have high conservation value.

In Italy, the first law that puts the rural buildings within the planning regulation is the $765 / 1967$, known as the bridge law because this law was responsible for establishing some basic principles in anticipation of a new national planning law. Actually, a new one has not yet replaced the first national planning law (1150/1942). At regional level, however, all the regions of Italy have legislated autonomously. For what concerns the rural buildings an obligation has been included to make a census of the same and to protect those of historical and cultural value as landscape assets. For example, in Umbria (a region of central Italy) the regional law $11 / 2005$, replaced by the law $1 / 2015$, provides for an obligation on the part of municipalities to identify in the planning instruments buildings scattered in the territory constituting property of historical, architectural and cultural interest (art. 89, comma 4, LR1/2015). The totality of rural buildings arose with exclusively or partly residential function is considered landscape assets (LR 1/2015, Umbria Region).

\section{Vernacular buildings and reduction of land consumption}

Since the mid 50's, the totality of urban areas in the EU increased by $78 \%$ compared to a population growth of $33 \%$ (SWD (2012)101 final). Between 1990 and 2006 the built surface in Europe and in Italy grew by $9 \%$ against a $5 \%$ increase in population (European Environment Agency, 2006).

Europe, pursuing an efficient use of resources, has set the goal by 2020 that Community strategies have to take into account the direct and indirect effects of land use and that by 2050 the increase in the net share of land use tends to zero $(\mathrm{COM}(2011) 571)$.

At the national level continues the trend to urban sprawl, as evidenced by the Degree of urban dispersion increasing from 45.37 Urban Permeation Unit $/ \mathrm{m}^{2}$ in 2006 to 45.39 in 2009 (European Environment Agency, 2016).

Whereas on the one hand the demand for residential construction in non-urban environment and on the other the need to reduce the consumption of soil, the re-functionalisation of farmhouses largely abandoned is of extreme interest.

Analysing the census of scattered buildings in the main Municipality of Umbria, Perugia, it indicates that $65 \%$ of buildings are classified as $\mathrm{CC}$ and that the $52 \%$ of these are abandoned buildings (Comune di Perugia, 2016). For this reason, we have chosen to use a CC typical of central Italy as a case study.

\section{Vernacular buildings and energy efficiency}

Parallel to the issue of land use runs the energy consumption issue: to reduce primary energy demand in the residential sector is a priority at both European and national level. In 2014 energy consumption related to the residential sector amounted in Europe and in Italy to $25 \%$ and $26 \%$ of total consumption respectively (Eurostat, 2014). The latest trends at community level are going toward making net zero energy buildings, including the refurbishment of existing buildings (European Directives 2010/31/EC and 2012/27/EU).

In favour of this kind of intervention, since year 2007 the Italian legislation has arranged the possibility of obtaining tax deductions of expenditure incurred for the implementation of energy saving measures of the existing buildings. Currently (2017), it is possible to deduct such expenses form the tax income return. Interventions should focus on passive solutions to improve the global energy efficiency of the building and active solutions to optimise the use of renewable energies (Menconi et al., 2016).

Both for the state of abandonment and for the technological evolution of the construction sector, the historic buildings need or may benefit from energy requalification to elevate performance standards (Picuno, 2016). From the point of view of architectural and technological design, it becomes fundamental the orientation, the use of natural materials and natural factors such as lighting and ventilation (Picuno, 2016). All of them are features that already distinguish rural traditional houses and which must necessarily be taken into account in the evaluation of a recovery or improvement intervention.

As the CCs of central Italy are protected from a landscape point of view, it is not possible to intervene on the building's facade by changing the openings, adding solar greenhouses, chimneys for ventilation, external insulation materials. For this reason, it was decided to focus the work on the study of optimal insulation materials to be added inside of the building and their optimal placement.

The CCs of central Italy are all prior to the nineteenth century, so it has confirmed the interest in intervening on this type of building, because it could be easy to reach thermal comfort conditions using passive solutions.

\section{Thermal dynamic simulations coupled with optimisation techniques}

The application of computational simulation methods for the resolution of complex engineering systems turned out to be a useful strategy. In particular, the application of dynamic simulation programs for the analysis of the thermal and energy behaviour of buildings in relation to specific goals, such as the reduction of consumption and environmental impacts or the improvement indoor thermal comfort conditions, is very significant (Menconi and Grohmann, 2014; Menconi et al., 2014). To improve the performance of a building a common approach used in the simulation field is a parametric analysis in which the input data for each variable are changed, run after run, to see the effects that these variations produce on design objectives. The main issues related to this approach are the enormous expenditure of time required to effectively exploring the search space and the uncertainty of the result due to the complex and non-linear interaction between the variables and the results of the simulation. The problem can be addressed by solving the system iteratively through computerised automatic procedures, which gets closer, run after run, to the optimal solution or to the sub-optimal solutions. In fact, in the field of simulation performance of buildings optimisation does not neces- 
sarily imply the identification of global optimal solution (Wetter and Wright, 2004). This method is often referred to as simulationbased optimisation and involves the coupling of a simulation program with one or more optimisation algorithms (Attia et al., 2013).

\section{Optimisation algorithms}

The main algorithms used in the field of simulation-based optimisation can be classified into three categories: enumerative, calculus-based, and random (Goldberg, 1989).

The enumerative algorithms investigate the search space, be it finite or infinite as long as discretised, point-by-point, analysing the values of the objective function. Despite their simplicity, these kinds of systems are lacking efficiency; in fact, they are heavy from the computational point of view and do not adapt well to explore a vast space of solutions.

The calculus-based algorithms work by gradients, looking for solutions with the least gradient or a gradient vector of zero, or work building a sequence that converges to a stationary point. These algorithms need that the function to be tested have special properties such as continuity and differentiability, for this reason are not the best solution to treat discontinuous and highly constrained issues, as often happens in the case of the optimisation of buildings and air-conditioning systems solution (Wetter and Wright, 2004).

Stochastic algorithms explore the search space in a semi-random modality. The drawback of this type of algorithms is that they can fall into local minima and remain so far from the optimal solution, especially if a reduced number of evaluations of the objective function are predisposed (Attia et al., 2013). The choice of the optimisation algorithm to be applied to a specific problem is crucial in determining its effectiveness (Murray et al., 2014). Stochastic algorithms are those most frequently used for the optimisation of buildings and heating, ventilation and air conditioning systems (Nguyen et al., 2014). Between these algorithms predominate genetic algorithms due to their high efficiency in solving complex problems with non-regular objective functions and characterised by high noise (Asadi et al., 2012). A single objective genetic algorithm optimisation method is used in this paper to optimise the thermal comfort of a CC.

\section{Comfort models}

The primary purpose of a house is to mitigate the adverse weather conditions by offering protection and trying to guarantee to those who live in it the best attainable health conditions. This concept can be translated into quantifiable terms of thermal comfort estimate perceived inside the building.

In this paper, the model for the thermal comfort evaluation inside the building has as its basis the adaptive comfort model, which is flanked with the Fanger model.

\section{Adaptive comfort model}

The adaptive thermal comfort model conceives of the occupants of the building as an integrated component of the comfort system. Initial studies conducted by Nicol and Humphreys in the seventies on adaptive models, validated in subsequent years (Nicol and Humphreys, 2010), demonstrate that there is a close correlation between the temperature perceived as comfort inside a building, and average temperatures prevailing inside and outside the building. The adaptive approach led in 2004 to the drafting of the first standard on adaptive comfort ANSI/ASHRAE 55-2004R Thermal Environmental Conditions for Human Occupancy as an option for buildings without air-conditioning systems.
In 2007, the European project SCATS led to the formulation of an exclusively European adaptive comfort standard, EN 15251 (McCartney and Nicol, 2002).

The standards are very similar and contain simple linear equations relating the acceptable temperatures in naturally ventilated buildings with outside prevailing temperatures.

\section{Fanger model}

The Fanger (1970) model is based on comfort predicted mean vote and predicted percentage of dissatisfied indices as described in ISO 7730/2005. According to the Fanger model, the human thermal sensations are connected to the body in its entirety, in the form of thermal equilibrium, and are influenced by the level of physical activity, the degree of isolation of the clothes and by a series of environmental factors such as operating temperature, speed of air and moisture. When these factors are known it is possible to calculate the predicted mean vote, an index that predicts the value of the average rating of a large group of people on a ASHRAE 7-point thermal sensation scale based on body thermal sensations. The predicted percentage of dissatisfied index instead establishes a quantitative prediction of the percentage of people thermally dissatisfied by the temperature, too hot or too cold.

\section{Objective of the paper}

In this study, it is discussed the issue of traditional rural building energy efficiency trying to identify strengths and weaknesses of the architectural and technological solutions adopted by vernacular architecture through an integrated analysis of the buildingenvironment. Starting from the characterisation of a $\mathrm{CC}$ in central Italy, a 3D model of the building has been created and the simulation based optimisation process has been applied to it with the purpose to find those variables that affect the thermal comfort behaviour of the building envelope the most.

The main optimisation goals can be classified into the following groups: shape and layout of a building; geometry, density and position of the windows; building envelope and building materials; natural lighting and control of sun screens; natural ventilation strategies; dimensioning of heating ventilation and air conditioning systems; control of heating, ventilation, and air conditioning systems.

In this paper, the optimisation process provides different insulating materials to different components of the building envelope to improve the indoor thermal comfort conditions.

\section{Materials and methods}

In Figure 1 is graphically represented the method developed in the paper.

\section{Characterisation of rural vernacular buildings in cen- tral Italy}

The first step was the characterisation of rural vernacular buildings in central Italy. The CCs are scattered all over the national context, but the forms, materials and original functions of such buildings are closely linked to the socio-geographic context in which they occur. Therefore, it was chosen to focus on the development of a model type of a CC valid for central Italy. In this regard, an extensive literature search was carried out on the subject (Niccoli, 1902; Bonasera et al., 1955; Torreggiani and Tassinari, 2013). The results obtained were then verified by analysing the 
860 CCs surveyed by the scattered rural building census of the Municipality of Perugia (Comune di Perugia, 2016).

\section{Development of the computer model of the building}

The second phase regards the development of the 3D model of the building. In this paper, EnergyPlus is the energy performance simulation program used. EnergyPlus works under dynamic conditions and was developed by the Department of Energy of the United States of America. It requires the following input data for the calculation of the heat balance: climate data, geometry, properties of materials, zoning, internal loads, heating, ventilation, and air conditioning (HVAC) systems and natural ventilation/infiltration. The heat and mass balance is carried out for each zone in which the building is divided and for each time step in which the overall time span examined in the simulation is subdivided. The model building has a thermal zone per floor, because the first division in six zones following the arrangement of the interior did not produce significant results. Simulations for this study were conducted using the Perugia weather file available on the U.S. Department of Energy website (https://energyplus.net/weather). Its main features are summarised in a previous work (Menconi and Grohmann, 2014). The simulation period examined in our study is one year because we wanted to analyse the behaviour of the building for an entire seasonal cycle. The methodology uses a dynamic thermal simulation engine that processes data with a time step of $10 \mathrm{~min}$. The geometry and the materials chosen for the model respect the original characterisation (see paragraph Characterisation of rural vernacular buildings in central Italy),

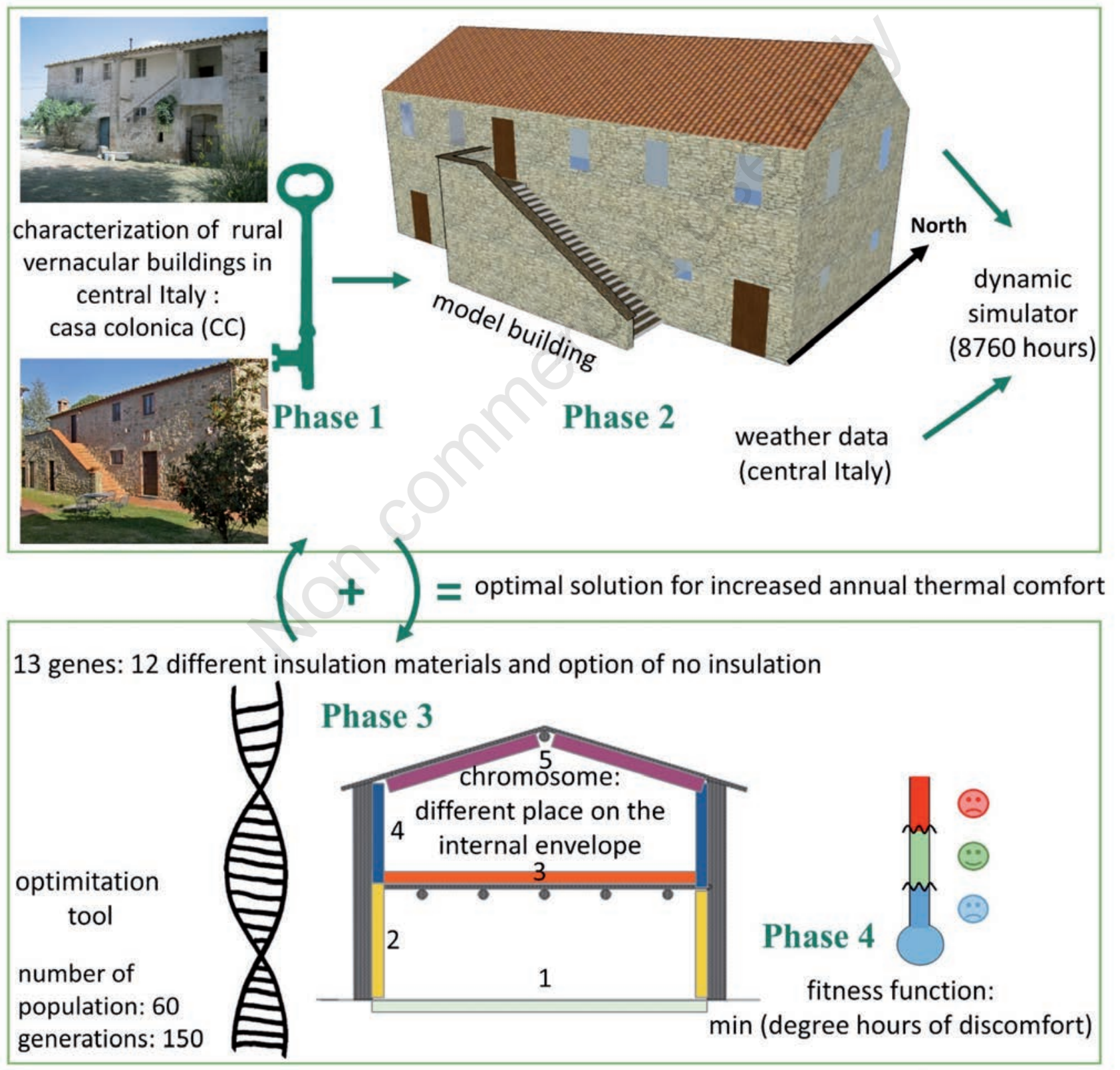

Figure 1. Graphical representation of the method's four phases. 
except for the glaze of the windows, since most of the transparent surfaces of the abandoned buildings are in severely degraded conditions or are completely absent. It was chosen to replace single glazing with a standard double glass with a thermal transmittance of $1.1 \mathrm{~W} / \mathrm{m}^{2} \mathrm{~K}$. This action is allowed in traditional buildings by the legislation, has no impact on the aesthetics of the building and the simulations show that alone already allows a reduction of about $2 \%$ of energy consumption on an annual basis. The thermo-physical characteristics of the materials have been obtained by the ISO 10456 (2007), the UNI/TS 11330 (2008) and the material database of the simulation program EnergyPlus. Usually, the impact of traditional stonewall's core of molten material is not taken into account in the simulation programs which consider the wall structure as a single and homogeneous block of stone. Traditional elements tend to behave thermally in a better way than one would expect from the analytically calculated transmittance. The comparison between in situ measurements and calculated values shows that generally the mortar not considered in the calculation leads to an overestimation of the values of transmittance. For the calculation of the transmittance, a proportion stone/mortar 60/40 can be considered more effective in realistic modelling of traditional stonewalls (Baker, 2011). Without mortar, transmittance of the wall of the ground floor is $2.416 \mathrm{~W} / \mathrm{m}^{2} \mathrm{~K}$ while that of the wall of the first floor is $2.869 \mathrm{~W} / \mathrm{m}^{2} \mathrm{~K}$. Insertion of mortar (conductivity 0.8 $\mathrm{W} / \mathrm{mK}$ ) in proportion of $40 \%$ on the total thickness, leads to a reduction of transmittance of the ground level wall to a value of $1.814 \mathrm{~W} / \mathrm{m}^{2} \mathrm{~K}$ and $2.088 \mathrm{~W} / \mathrm{m}^{2} \mathrm{~K}$ on the first floor wall.

For the evaluation of the internal loads by the occupants and equipment, the data were imported from the recommended values reported in the UNI/TS 11300 for the category residential building.

In the model used, the house is heated with an ideal HVAC system with intermittent operation: $12 \mathrm{~h}$ of total heating divided into 4 intervals of $3 \mathrm{~h}$ each distributed uniformly within the $24 \mathrm{~h}$. The thermostat set point was set to $22^{\circ} \mathrm{C}$ of operative temperature (OT) according to the comfort OT of $22.15^{\circ} \mathrm{C}$ derived from the Fanger model (predicted mean vote $=0)(\mathrm{CEN}, 2007)$ with a level of activity equal to 1.2 met (metabolic equivalent) and 1 clo the degree of insulation cloth. Heating is only active on the first floor, since we decided to leave the ground floor area unconditioned in accordance with the original vocation of this space used as storage, cellar and stable. Solely for the purpose of aeration, it was set a constant natural ventilation (air inlet temperature equal to the outdoor temperature) air exchange rate of $0.3 \mathrm{vol} / \mathrm{h}$ as recommended by the UNI TS 11300 . During the heating season and outside of the validity limits of the adaptive model, the European legislation 15251 (CEN, 2007) suggests to use Fanger model for the determination of the occupants' thermal comfort OTs and the related classes of thermal comfort, by setting appropriate values for activity levels and insulation of the clothes of the occupants. In our case we decided to use fixed values for the entire heating season, respectively 1.2 met and 1 clo. It was decided to begin the heating season when the average outdoor dry bulb air temperature, running mean temperature $(\mathrm{CEN}, 2007)$ falls permanently below $15^{\circ} \mathrm{C}$ because in these conditions the lower limit of the adaptive model loses meaning and it is easily possible to switch to the Fanger model. The season ends when running mean temperature again exceeds $15^{\circ} \mathrm{C}$.

\section{Choice of design variables to be optimised}

The third phase regards the choice of the design variables to be optimised. The variables chosen are 12 different insulation materials (Table 1) positionable in 5 different parts of the building envelope: pavements and vertical walls of the ground floor, pavements and vertical walls of the first floor and roof. It was then added a thirteenth variable to consider the option of non-intervention, as well. The traditional historic buildings present constraints on facade modification, so the layers to optimise the energy efficiency were added only on the inside.

\section{Definition of the objective function}

The fourth phase regards the definition of the objective function. It was decided to use an indicator of the level of thermal discomfort inside the building on annual basis. Technical standards EN 15251 recommends to use the Hours Degree Method (CEN, 2007) as an indicator of the thermal performance of the building. In this method, the total time during which the OT falls outside of a specific range, weighed on how much the limit has been exceeded, is calculated. The chosen limits were the second thermal comfort category: equivalent to $3^{\circ} \mathrm{C}$ below and above the comfort temperature in the adaptive model and the temperature related to a predicted mean vote of $+/-0.5$ for the Fanger model.

For the calculation of the discomfort degree hours (DDH) the following two equations were used:

$$
\begin{aligned}
& \mathrm{DDH}=(\text { ACT2low-ZOT }) * 10 / 60 \\
& \mathrm{DDH}=(\text { ZOT-ACT2up }) * 10 / 60
\end{aligned}
$$

\begin{tabular}{|c|c|c|c|c|}
\hline Material & Conductivity (W/mK) & Density $\left(\mathrm{kg} / \mathrm{m}^{3}\right)$ & Specific heat (J/kgK) & Thermal diffusivity $\left(\mathrm{m}^{2} / \mathrm{s}\right)$ \\
\hline Mineralised wood & 0.067 & 400 & 2100 & 0.8 \\
\hline Cork & 0.04 & 150 & 2100 & 1.3 \\
\hline Plywood & 0.12 & 540 & 1210 & 1.8 \\
\hline Glass fibre & 0.036 & 140 & 960 & 2.6 \\
\hline Autoclaved aerated concrete & 0.045 & 110 & 1300 & 3.1 \\
\hline Gypsum-fibre & 0.24 & 816 & 880 & 3.3 \\
\hline Cellular polyurethane & 0.0245 & 24 & 1590 & 6.4 \\
\hline Brick - fired clay & 0.34 & 2400 & 790 & 7.0 \\
\hline Stone aggregate concrete & 1.95 & 2240 & 900 & 9.7 \\
\hline Sheep wool & 0.037 & 18 & 1720 & 12 \\
\hline Expanded polystyrene & 0.036 & 20 & 1210 & 14.8 \\
\hline Expanded perlite & 0.052 & 16 & 1260 & 25.8 \\
\hline
\end{tabular}

Table 1. The insulation materials used as optimisation variables (genes). 
where ACT2low is the lower limit of the II comfort category; ZOT is the zone operating temperature; ACT2up is the upper limit of the II comfort category. Equation number 1 is used if ZOT < ACT2low, while equation number 2 if ZOT $>$ ACT2up. The 10/60 multiplier is a conversion factor needed to switch from minutes to hours as the simulation engine processes data with a time step of $10 \mathrm{~min}$. The objective function is to find the minimum of DDH.

The structure of the optimisation model and the connection between the simulation program and the optimisation algorithm were made with the programming language MATLAB.

\section{Results}

\section{Characterisation of rural vernacular buildings in cen- tral Italy}

The most common type of vernacular rural buildings in the central Italy belongs to the unitary housing typology with living space on the first floor and rustic space on the ground floor, with external staircase and a gabled roof (Figure 1) (Bonasera et al., 1955). The rustic space (ground floor) traditionally fulfilled multiple purposes: barn, warehouse, cellar and tool shed. The census shows for the category CC that the most common volume is 1000 $\mathrm{m}^{3}$ (Comune di Perugia, 2016). From these data and construction features reported in literature (Niccoli, 1902) it was possible to derive the sise of our CC basic model (Figure 1). The building is oriented with the long side containing the stairway facing south. The windows of the ground floor have square shape and smaller size as the ground floor was originally used as a shelter for animals.

Exterior walls have a structure typical of traditional stonewalls of considerable thickness, the whole structure is held together by mortar of lime and sand. The load bearing walls have a thickness of $40 \mathrm{~cm}$ on the first floor and $55 \mathrm{~cm}$ on the ground floor. The interior non-load bearing walls are instead made by solid bricks of 15 $\mathrm{cm}$ length. External and internal walls have a plaster layer of $2 \mathrm{~cm}$, only on the inside face for the external walls, on both sides for internal walls. The floor of the ground floor consists of a layer of concrete topped with ceramic tiles (Niccoli, 1902). The first floor consists of a wooden truss on which rests a layer of bricks, one of loose material (sand and gravel) and another one of bricks. The roof is made of a layer of tiles, which rests atop a wooden truss, topped by roof tiles. External and internal doors are made of wood and have a thickness respectively of 5 and $2 \mathrm{~cm}$. The windows are single glazing not coloured.

The CC model was built based on these results. Figure 1 shows the layout of the CC model and the characteristics of his envelope are shown in Table 2 .

\section{Casa colonica model's efficiency: thermal comfort and energy consumption}

The simulation results show that the $\mathrm{CC}$ has an annual $\mathrm{DDH}$ value equal to 15,889 . Figure 2 shows the trend of the OT in the yearly simulation for the inhabited area of the building (first floor). Starting from the considerations set out in a previous paragraph (Development of the computer model of the building), the heating season runs from January $1^{\text {st }}$ to April $18^{\text {th }}$ and from October $8^{\text {th }}$ to December $31^{\text {st }}$. The trend of the OT has values fluctuating both during the heating season and during the rest of the year. In the first case, this is caused by the intermittent operation of the heating sys- tem, in the second because of the variation of the external temperature between day and night. The DDH associated with the heating season are $12,076(76 \%$ of the annual total) those associated with the season without heating are 3813 (24\%). The energy consumption related to heating amounted to $161.90 \mathrm{GJ}$ per year.

These first results show that the CC model has better overall thermal performance during the hot season, so the optimisation process should identify intervention configurations affecting most significantly during the cold season.

\section{Casa colonica optimal model}

In a previous study, a parametric analysis of genetic algorithm's performances was carried out to address the effects induced by four parameters of the algorithm: population size, crossover probability, mutation probability, encoding and reproduction strategy (Menconi et al., 2013). Consequently, we have used a population of 60 individuals, a crossover probability of 0.9 , a mutation probability of 0.1 , a binary coding and an elitist reproduction strategy.

Initially 150 generations were set, but the optimisation terminated at 112 generations as the average change in the penalty Fitness value was less than the tolerance value (Figure 3).

The optimal solution provides as insulating materials: the use of polyurethane on the walls and on the roof, and the use of mineralised wood on the first floor pavement. As regards the ground floor, the model does not foresee the use of any horizontal layer.

Figure 4 shows the comparison between the $\mathrm{CC}$ model and the CC optimal model. The total DDH drop to 3345 and the energy consumed to $36.96 \mathrm{GJ}$, getting an improvement on the CC model by 79 and $77 \%$.

During heating season to the CC optimal model corresponds $1739 \mathrm{DDH}$ (52\% of total). In the unheated period were instead calculated $1606 \mathrm{DDH}(48 \%)$.

The amplitude of the oscillations for the optimised case is much reduced both in the heating season and in the rest of the year. This reduction brings the OT more frequently back in regions of thermal comfort as confirmed by the sharp decline of DDH. This applies particularly for the cold season where the minimum of the OT values is close to the lower limit. In the hot season, the addition of insulating material helps to dampen and delay the peak temperature, but at the same time it moves upward the average trend of OTs. This is beneficial at the end of the heating season when outdoor temperatures are on average still low (between 20 and $10^{\circ} \mathrm{C}$ ), but is counterproductive in the hot peak period.

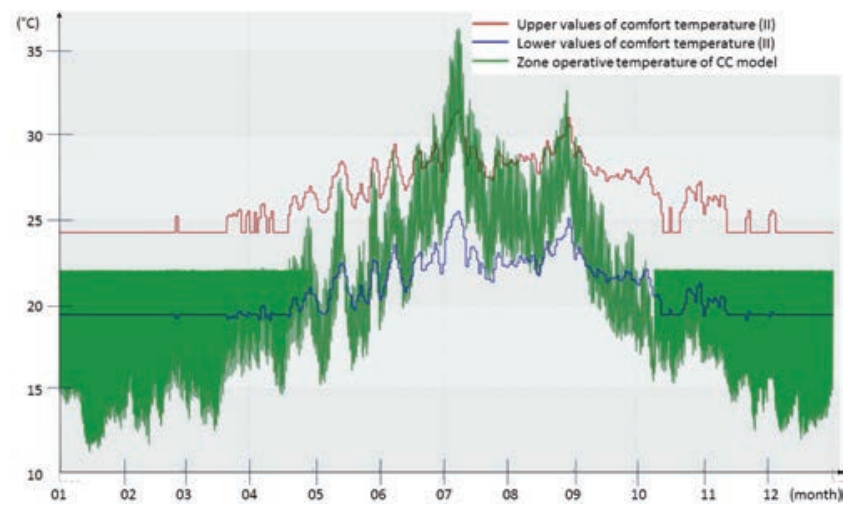

Figure 2. Hourly operative temperature values for the casa colonica (CC) model during one year of simulation. 


\section{Discussion and conclusions}

\section{Results of sensitivity analysis}

In order to study the impact of the different placement of insulating materials inside the envelope of the buildings in the determination of the optimal solution (CC optimal model) has been set a parametric sensitivity analysis.

The analysis foresees to eliminate from the optimal solution an additional insulating layer at a time by analysing the results of the simulations in different periods of the year: all year, heating period, not heating period, coldest month (January) and hottest month (July).

Table 3 shows the results of this analysis in terms of thermal comfort achieved, normalised according to the criterion of the minimum and maximum. The value one corresponds to the ideal solution, which does not provide moments of thermal discomfort (ideal solution) and 0 to the solution that has a greater number of $\mathrm{DDH}$

Table 2. Case study building: characteristics of the envelope.

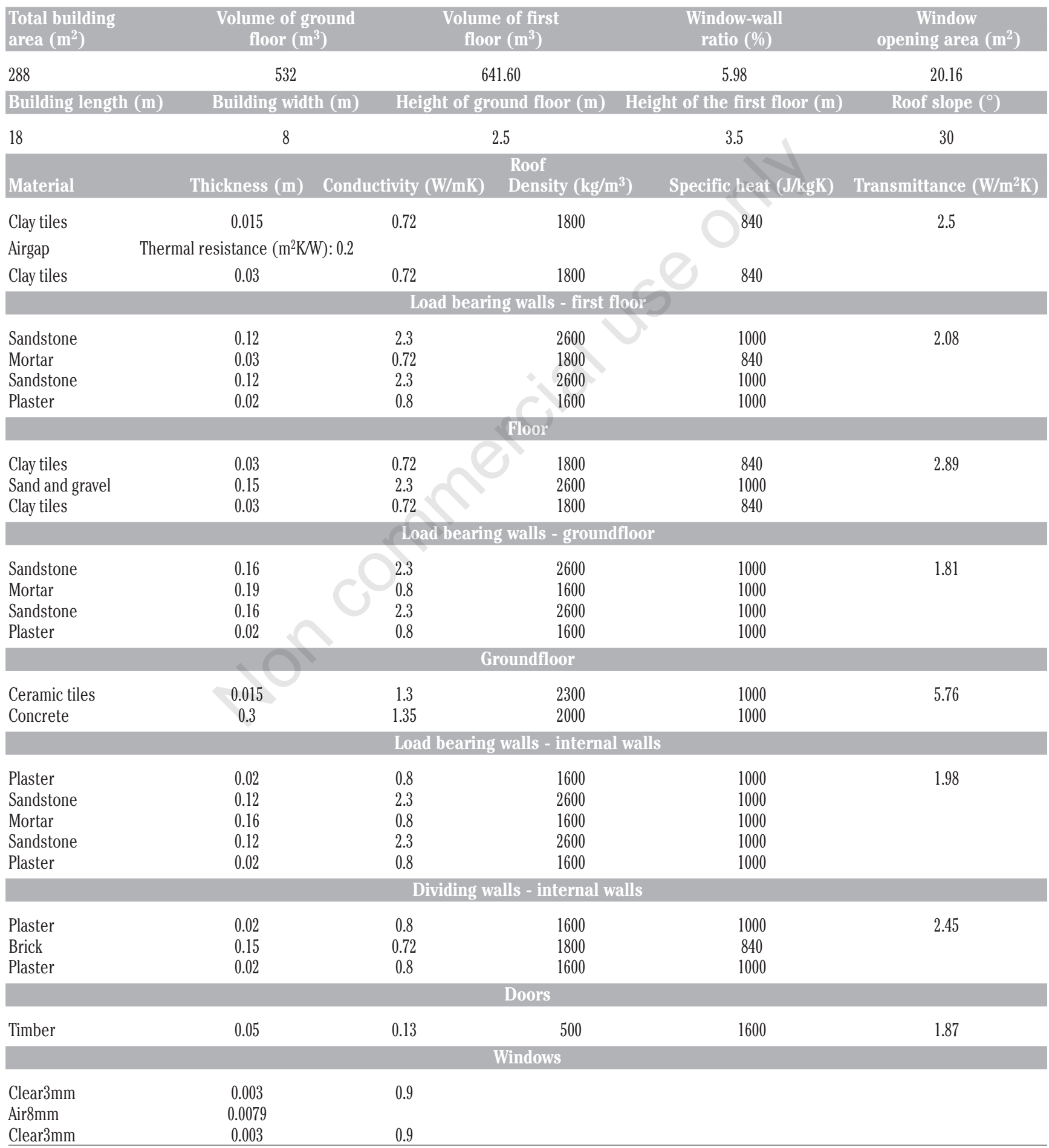


in the analysed periods. From this Table it can be seen that the CC optimal model has a higher efficiency in the cold months by presenting a performance of 0.81 and 0.78 . These values are higher than the annual value of 0.76 .

Table 4 allows reading more intuitively the influence of the different insulating layers on the CC optimal model.

In the hottest month, the CC optimal model turns out to be a pejorative solution compared to no intervention ( $\mathrm{CC}$ model). In fact, in July the solution with better performance is to insulate only the outer opaque surfaces (walls and roof).

The data can be interpreted in light of the fact that the pavement of the first floor separates air-conditioned environments from non-air-conditioned ones, located on the ground floor. In summer, in the absence of cooling systems, the lowest temperatures recorded on the ground floor, due to greater thickness of the walls, reduced solar gains, due to smaller openings, and direct contact with the ground, are beneficial to the overlying area. During the cold season, however, the lack of insulation in the floor has a considerable weight in determining the thermal discomfort of the first floor with a reduction of $\mathrm{P}$ by $27 \%$ compared to the optimal solution for the air-conditioned period and $24 \%$ for the coldest month. The contrasting behaviour between summer and winter performances of the first floor's pavement provides a justification for dif- ferent conductivity associated with the material placed in the floor from the optimisation process compared to other surfaces. In fact, the process of optimisation has selected for this spot a material with a low conductivity $(0.067 \mathrm{~W} / \mathrm{mK})$ to isolate during the cold season but not the minimum $(0.024 \mathrm{~W} / \mathrm{mK})$ in order to ensure heat exchange between the first floor and ground floor anyway during the hot season.

The data shows that the roof insulation is, in all analysed periods, the most influential and to neglect this component brings a significant deterioration compared to the optimal solution. The layers that are less influential are the ground floor walls, whose contribution is always close to zero. The absence of any insulation on these layers leads to very similar performance to that of the optimal solution.

\section{Critical issues and future developments}

Below are summarised the main critical points and future developments:

- The presented papers focused on the technical analysis of building insulation materials. The paper identify polyurethane has the best response in terms of temperature control but the method used has left out any cost implications and life cycle assessment (LCA) approach. The legislation on energy effi-

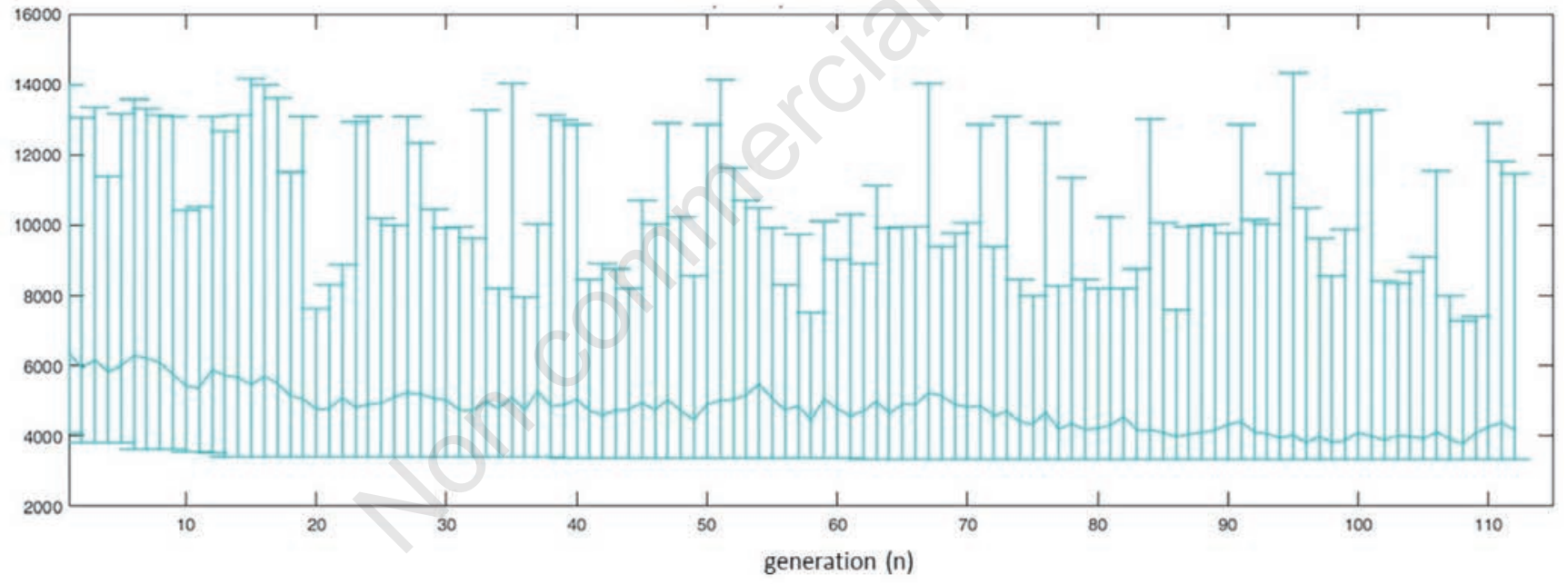

Figure 3. Trend of the optimisation process.

Table 3. Results of the parametric sensitivity analysis showing the impact of the different placement of insulating materials inside the envelope of the buildings in the determination of the optimal solution (casa colonica optimal model).

\begin{tabular}{lccccc} 
& Full year & $\begin{array}{c}\text { Heating } \\
\text { period }\end{array}$ & $\begin{array}{c}\text { Unheated } \\
\text { period }\end{array}$ & $\begin{array}{c}\text { Coldest month } \\
\text { (January) }\end{array}$ & $\begin{array}{c}\text { Hottest } \\
\text { month (July) }\end{array}$ \\
CC model & 0.00 & 0.00 & 0.32 & 0.00 & 0.59 \\
CC optimal model without roof insulation & 0.15 & 0.36 & 0.00 & 0.34 & 0.00 \\
\hline CC optimal model without insulation of vertical walls of the first floor & 0.51 & 0.54 & 0.61 & 0.52 & 0.64 \\
CC optimal model without insulation of ground floor's pavement & 0.50 & 0.59 & 0.47 & 0.59 & 0.78 \\
\hline CC optimal model without insulation of vertical walls of the ground floor & 0.75 & 0.81 & 0.71 & 0.99 \\
CC optimal model & 0.76 & 0.81 & 0.73 & 0.78 & 0.47 \\
\hline Ideal solution & 1 & 1 & 1 & 1 & 1 \\
\hline
\end{tabular}

$\mathrm{CC}$, casa colonica. 
ciency in buildings EPBD pays particular attention to identifying the most effective solutions in terms of costs (European Directive 2010/31/EC) and there is a vast literature on LCA and life cycle costing approach (Menconi and Grohmann, 2014). The developed methodology can be expanded by implementing a multi-objective procedure that takes into account multiple functions simultaneously.

- The work focused only on the evaluation of optimal insulation materials to be added to the envelope, but subsequent developments will consider other aspects investigated in the literature relating to natural lighting and control of sun screens, natural ventilation strategies, dimensioning and control of heating, ventilation, and air conditioning systems (Sun and Leng, 2015).

- Two different models of thermal comfort have been combined, one suitable for air-conditioned buildings and one designed for naturally ventilated buildings, providing an abrupt transition from one to another. The evaluation of thermal comfort, therefore, is highly uncertain if taken in absolute value, but as it is used to compare alternative solutions, the simplification choice is acceptable (Fanger, 1970; Nicol and Humphreys, 2010).

\section{Conclusions: bullet points}

Below are summarised the main contributions of this paper:

- Vernacular building characterisation. The legislation governing the recovery of the housing stock of historical, architectural, and cultural interest in Italy provides useful information on general and typological characteristics of traditional rural building in order to identify and classify these assets (Bonasera et al., 1955; Comune Perugia, 2016). However, in the literature it is not provided any specific information in the thermo-physical characterisation of the elements used in local traditional building to address energy diagnosis. This work offers a contribution in this direction by connecting constructive and energy information.

- Development of a methodology for optimising the thermal comfort of vernacular buildings. In this paper has been applied a methodology which involves the application of a simulationbased optimisation model applied to traditional local rural buildings, in this specific case the farmhouses of central Italy. The model can be used to optimise real cases detailing a large number of parameters, reported in our case in a simplified manner, such as the occupancy level of the environments, the intended use of the premises, the internal heat loads, type and operation of the installations, etc.

Impact assessment of the various parts of the building envelope on thermal comfort. The optimisation process and the following sensitivity analysis have highlighted some important aspects to consider when approaching an intervention of energy requalification on a building's envelope. If, in general, to isolate the opaque surfaces it is necessary for a global improvement of the performance of the building, not all surfaces contribute equally to the achievement of thermal comfort and not all surfaces need the same degree of isolation. Parametric analysis shows that the roof is the most influential component, both during the heating season than in the rest of the year. The insulation of the ground floor is negligible in determining the upper level comfort.

- Importance of simulations on an annual basis. The optimisation process has shown that the lower is the conductivity of the insulation material, the greater is the reachable thermal comfort. This statement does not apply to the first floor pavement where a lower conductivity is advantageous in the warm periods to allow greater exchange between the first and the ground floor, where there are lower temperatures. Efficiency improvements with positive effects during the cold season may prove

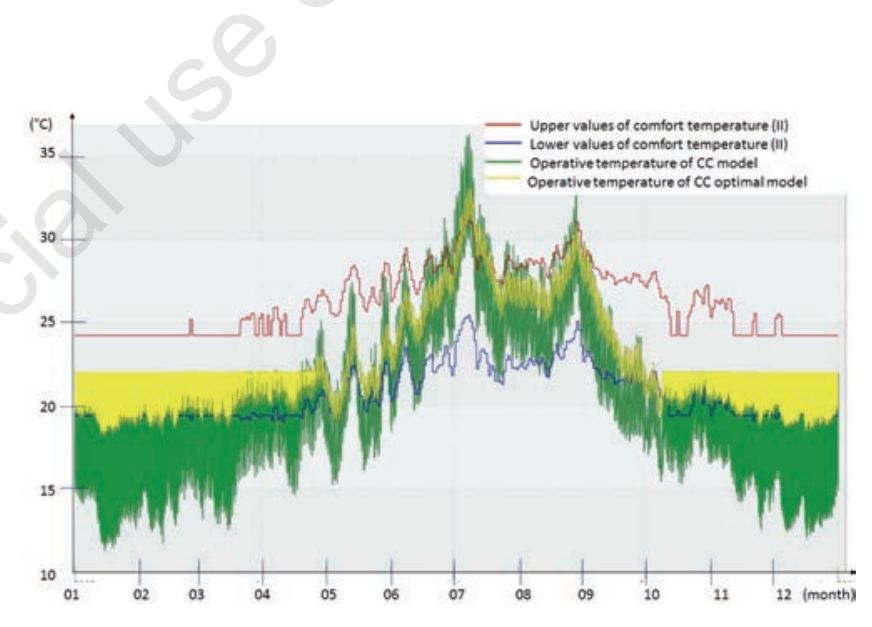

Figure 4. Comparison between hourly operative temperature values for the casa colonica (CC) model and the CC optimal model during one year of simulation.

Table 4. Efficiency of the analysed solutions compared to the building thermal comfort. To the casa colonica (CC) optimal model has been assigned an efficiency of $100 \%$. Those solutions that have a higher efficiency are improved solutions compared to the proposed model for the period to which they relate (CC optimal model without insulation of vertical walls of the first floor and CC optimal model without insulation of ground floor's pavement during the hottest month). The solutions with an efficiency close to 100 (CC optimal model without insulation of vertical walls of the ground floor during heating period) show that the eliminated layer (insulation of vertical wall) has a negligible impact on the thermal comfort for the period under consideration (heating period and coldest month). The solutions with an efficiency close to 0 (CC optimal model without roof insulation) instead demonstrate the extreme value of the eliminated layer (roof insulation).

\begin{tabular}{lccccc} 
& $\begin{array}{c}\text { Full year } \\
(\%)\end{array}$ & $\begin{array}{c}\text { Heating } \\
\text { period (\%) }\end{array}$ & $\begin{array}{c}\text { Unheated } \\
\text { period (\%) }\end{array}$ & $\begin{array}{c}\text { Coldest month } \\
\text { (January) (\%) }\end{array}$ & $\begin{array}{c}\text { Hottest month } \\
\text { (July) (100) }\end{array}$ \\
CC optimal model without roof insulation & 19.74 & 44.44 & 0.00 & 43.59 & 0.00 \\
CC optimal model without insulation of vertical walls of the first floor & 67.11 & 66.67 & 83.56 & 66.67 & 136.17 \\
\hline CC optimal model without insulation of ground floor's pavement & 65.79 & 72.84 & 64.38 & 75.64 & 210.64 \\
CC optimal model without insulation of vertical walls of the ground floor & 98.68 & 100.00 & 97.26 & 100.00 & 91.49 \\
\hline CC optimal model & 100.00 & 100.00 & 100.00 & 100.00 & 100.00 \\
\hline
\end{tabular}

CC, casa colonica. 
counterproductive in the hot season and vice versa. That is why an annual evaluation of the thermal comfort is useful in identifying the globally best solutions in our latitudes, and for the class of buildings covered in this paper.

- Efficiency of simple passive solutions. This paper shows how using only passive solutions it is possible to increase significantly the indoor thermal comfort in vernacular rural buildings of central Italy, in line with the results found in other geographical contexts for different traditional buildings (Sun and Leng, 2015). In particular, the thermal comfort of a typical rural building of central Italy can be increased by $79 \%$ using only insulation materials added to the internal envelope.

\section{References}

Asadi E., da Silva M.G., Antunes C.H., Dias L. 2012. A multiobjective optimisation model for building retrofit strategies using TRNSYS simulations, GenOpt and MATLAB. Build. Environ. 56:370-8.

Attia S., Hamdy M., O’Brien W., Carlucci S. 2013. Assessing gaps and needs for integrating building performance optimisation tools in net zero energy buildings design. Energ. Build. 60:11024.

Baker P. 2011. U-values and traditional buildings, In situ measurements and their comparison to calculated values. Historic Scotland Technical paper 10. Historic Scotland Conservation Group, Edinburgh, Scotland.

Bonasera F., Desplanques H., Fondi M., Poeta A. 1955. La Casa Rurale in Umbria [Rural building in Umbria]. In: Consiglio Nazionale delle Ricerche (Ed.), Ricerche sulle dimore rurali in Italia, Vol. 14. L.S. Olschki, Firenze, Italy [in Italian].

CEN (Comite Europe en de Normalisation). 2007. Indoor environmental input parameters for design and assessment of energy performance of buildings: addressing indoor air quality, thermal environment, lighting and acoustics. CEN 15251:2007. Comite Europe en de Normalisation, Brussel, Belgium.

Comune di Perugia. 2016. Ricognizione dei vincoli paesaggistici riferiti al D Lgs. 42/04 Codice dei Beni culturali e del paesaggio e delle componenti della pianificazione paesaggistica locale, Allegato A3_2, Altre componenti paesaggistiche, in: Piano Regolatore Generale. Available from: http://istituzionale.comune.perugia.it/pagine/vincoli Accessed: January 2017.

European Environment Agency. 2006. Urban sprawl in Europe, The ignored challenge, EEA 10/2006. Publications Office of the European Union, Luxemburg.

European Environment Agency. 2016. Urban sprawl in Europe, joint EEA-FOEN report, EEA 11/2016. Publications Office of the European Union, Luxembourg.

Eurostat. 2014. Final energy consumption by sector, Eurostat Energy Survey. Available from: http://ec.europa.eu/eurostat/ tgm/table.do?tab=table\&init $=1 \&$ language $=$ en $\&$ pcode $=$ tsdpc 3 20\&plugin=1 Accessed: January 2017.

Fanger P.O. 1970. Thermal comfort. Danish Technical Press,
Copenhagen, Denmark.

Goldberg D.E. 1989. Genetic algorithms in search, optimisation, and machine learning, reading. Addison-Wesley, Boston, MA, USA.

McCartney J.K., Nicol J.F. 2002. Developing an adaptive control algorithm for Europe: results of the SCATs project. Energ. Build. 34:623-35.

Menconi M.E., Chiappini M., Grohmann D. 2013. Implementation of a genetic algorithm for energy design optimisation of livestock housing using a dynamic thermal simulator. J. Agricult. Engine. 44(s2):191-6.

Menconi M.E., Dell'Anna S., Scarlato A, Grohmann D. 2016. Energy sovereignty in Italian inner areas: Off-grid renewable solutions for isolated systems and rural buildings. Renew. Energ. 93:14-26.

Menconi M.E., Grohmann D. 2014. Model integrated of life-cycle costing and dynamic thermal simulation (MILD) to evaluate roof insulation materials for existing livestock buildings. Energ. Build. 81:48-58.

Menconi M.E., Grohmann D. Borghi P. 2014. Dynamic thermal simulation on retrofitting scenarios for semi-extensive sheep farms. J. Agricult. Engine. 45:80-90.

Menconi M.E., Grohmann D., Mancinelli C. 2017. European farmers and participatory rural appraisal: A systematic literature review on experiences to optimise rural development. Land Use Policy 60:1-11.

Murray S.N., Walsh B.P., Kelliher D., O’Sullivan D.T.J. 2014. Multi-variable optimisation of thermal energy efficiency retrofitting of buildings using static modelling and genetic algorithms - A case study. Build. Environ. 75:98-107.

Nguyen A., Reiter S., Rigo P. 2014. A review on simulation-based optimisation methods applied to building performance analysis. Appl. Energ. 113:1043-58.

Niccoli V., 1902. Costruzione ed economia dei fabbricati rurali (Building and economy of rural buildings). Hoepli, Milan, Italy. [In Italian]

Nicol J.F., Humphreys M.A 2010. Derivation of the adaptive equations for thermal comfort in free-running buildings in European standard EN15251. Build. Environ. 45:11-7.

Picuno P. 2012. Vernacular farm buildings in landscape planning: a typological analysis in a southern Italian region. J. Agricult. Engine. 43:130-7.

Picuno P. 2016. Use of traditional material in farm buildings for a sustainable rural environment. Int. J. Sustain. Built Environ. 5:451-60.

Sun H., Leng M. 2015. Analysis on building energy performance of Tibetan traditional dwelling in cold rural area of Gannan. Energ. Build. 96:251-60.

Torregiani D., Tassinari P. 2013. Landscape quality of farm buildings: the evolution of the design approach in Italy. J. Cultural Heritaga 13:59-68.

Wetter M., Wright J.A. 2004. A comparison of deterministic and probabilistic optimisation algorithms for nonsmooth simulation-based optimisation. Build. Environ. 39:989-99. 